\title{
Evaluation of exposure to benzene vapour during the loading of petrol
}

\author{
R. J. SHERWOOD \\ Esso Europe Inc., London
}

\begin{abstract}
Sherwood, R. J. (1972). Brit. J. industr. Med., 29, 65-69. Evaluation of exposure to benzene vapour during loading of petrol. The exposure of three workers to benzene vapour has been determined by personal air sampling, and has been related to their intake (assessed by sampling exhaled breath), and to their metabolism of benzene (evaluated from the concentration of phenol in urine). The results obtained agree in general with those already published in the literature and with a preliminary experimental exposure undertaken as part of the development of techniques.

The two loaders who handled the loading arms were exposed to mean concentrations of 1.6 and 2.5 p.p.m. over the 5 -hour period of loading. The probability of their exposure to concentrations greater than 25 p.p.m. was about 0.1 and $1 \%$. The weigher working between the tracks was exposed to a mean concentration of 20 p.p.m. over the same period and had a total exposure of 114 p.p.m.-hour. Samples of exhaled breath taken at the end of work showed 0.14 and 0.18 p.p.m. benzene for the loaders and 0.84 p.p.m. for the weigher. The following morning the latter showed $0 \cdot 19$ p.p.m. Urine samples taken from the loaders at the end of work contained 12 and $25 \mathrm{mg} / \mathrm{l}$ total phenol and for the weigher $83 \mathrm{mg} / \mathrm{l}$. The following morning the phenol was not above natural levels in the loaders' urine, and was $38 \mathrm{mg} / \mathrm{l}$ in a sample from the weigher.

It is suggested that any or all of the methods developed for this study could be used in conjunction with appropriate clinical studies to provide a more quantitative basis for determining the hazard of occupational exposure to benzene.
\end{abstract}

As petrol may contain about $5 \%$ benzene, exposure to benzene vapour during the loading of this product has been determined at many plants in Europe and generally no significant exposure has been detected. Owing to a combination of factors-operational, structural, and meteorological-one particular installation in Italy could be identified as more likely to cause exposure than other facilities, and this has been studied in depth over a number of years.

During this time, the methods of measurement have been considerably improved, and in this paper only the most recent results are reported and dis- cussed as it is considered that they are the most definitive.

Benzene has been assessed because it is the only hydrocarbon component which is known to cause chronic disease if overexposure occurs. In this particular operation the acute toxicity of high concentrations of hydrocarbon vapours is considered to be of secondary importance.

This study had two objectives:

1. to determine exposure to, and intake of, benzene during work; and

2. to correlate air concentrations and biological 
indices of exposure, as recommended by the Joint ILO/WHO Committee on Occupational Health (1969).

\section{Description of plant and operation}

The installation is designed to load into rail tankers a variety of products, a considerable proportion of which comprises petrol containing some benzene.

Petrol is pumped from storage tanks to the loading rack and delivered to the rail tankers at a rate of 5000 $\mathrm{kg} / \mathrm{min}$ through flexibly jointed loading arms into open ports on top of these tankers by men stationed on each one (Fig. 1). The precise amount loaded is determined by weighing the trucks during the operation, and to do this one operator works in a small weigh room at ground level between each pair of tracks (Fig. 2).

During loading, some vapour escapes through the open truck ports and is dispersed by the wind. When there is little or no wind the heavy vapours fall down the side of the trucks to ground level and may enter the weigh room.

Although work continues throughout the 8-hour working day, the period of exposure to petrol vapour is considerably less as time is taken in moving trucks and loading other products.

\section{Evaluation techniques}

The three techniques employed in the study were:

1. to evaluate exposure to benzene by personal air sampling during work;

2. to evaluate intake by collecting samples of exhaled breath with breath sampling tube, and by sampling respirator, before and after work;

3. to evaluate the rate of benzene metabolism in the body by measuring the concentration of phenol in urine.

Details of the development or improvement of these

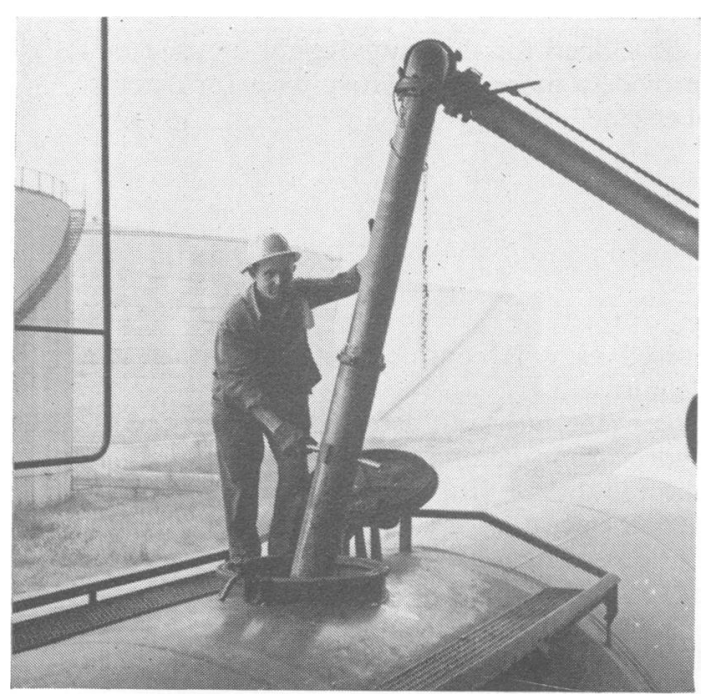

FIG. 1. Operator loading tanker.

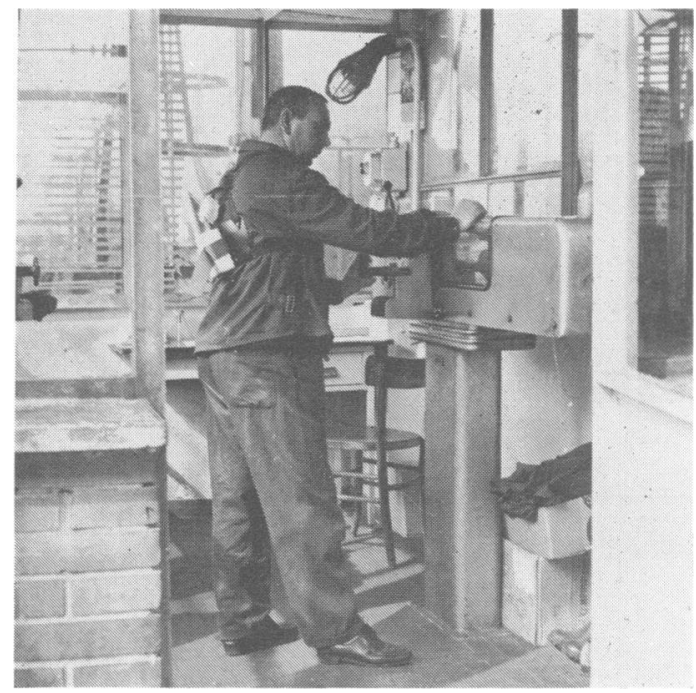

FIG. 2. Operator in weigh room.

methods have been published (Sherwood and Carter, 1970) and only the final techniques are summarized here.

\section{Personal air sampling}

To determine individual exposure to benzene vapour the standard personal air sampler was modified to make the electrical system intrinsically safe, and a new sampling head was developed to collect the vapour. The unit is designed to draw $11 / \mathrm{min}$ of air through a silica gel trap carried on the worker's shoulder. The benzene is subsequently eluted from the gel with absolute alcohol and the amount present is determined by gas chromatography of a portion.

\section{Exhaled breath sampling}

When benzene vapour is inhaled, some is absorbed into the blood. A part of this is metabolized and some is more slowly absorbed by other tissue, particularly the fat and bone marrow. When exposure ceases, much of the benzene circulating in the blood is rapidly exhaled (Hunter, 1968). This is followed (Sherwood and Carter 1970) by a period when benzene is probably being released from muscle tissue and elimination in breath is characterized by a half-life of half to one hour. Later still, halflife extends to half to one day and the benzene probably comes from the fatty tissues including the bone marrow. From this long-term component it is possible to estimate the amount of benzene stored in fatty tissue and this may be the best index of chronic hazard at present available.

Two techniques for the determination of the concentration in the breath for field use have been developed. The first, based on the technique of Stewart and Dodd (1964), employs small glass containers with polyester seals to collect the breath. On return to the laboratory, samples are withdrawn by syringe and injected directly into a gas chromatograph. The second method is more laborious than the first but probably provides more accurate results as benzene is trapped from all the breath 
exhaled over a 10-minute period. To do this, an additional cartridge has been fitted to the exhalation valve of an oronasal respirator, and the exhaled breath is passed through silica gel, as used in the personal air sampler, to trap the benzene. A similar analytical procedure is followed, and the weight gain of the cartridge due to adsorption of moisture from the breath permits the volume of exhaled air to be assessed.

\section{Urine sampling}

The principal metabolite of benzene is phenol which appears in urine within 24 hours of exposure, conjugated with sulphate or glucuronide. The concentration of phenol is determined in samples collected before and after exposure. To avoid interference from the cresols naturally present, a specific gas chromatographic technique is used. To determine the conjugated phenol, samples are initially hydrolysed with perchloric acid and the phenol is then extracted with diisopropyl ether.

As the concentration of phenol in urine is, in part, affected by the rate of urine excretion, results have been normalized by the rather arbitrary specific gravity correction method of Levine and Fahy (1945). The normal specific gravity is taken to be the mean specific gravity of all the samples analysed, rather than the values reported in the literature, 1.024 or 1.016 , and the correction is limited to a factor of 2 .

\section{Sensitivities of techniques}

If air samples are collected over periods of 15 minutes, average benzene concentrations as low as 0.02 p.p.m. (by volume) can be determined.

A similar concentration in exhaled breath can be determined by the respirator technique and about 0.05 p.p.m. by breath sample tube. These concentrations are likely to be present in breath 16 hours after exposure to $10-25$ p.p.m.-hours or immediately after working in a concentration of 0.2-1 p.p.m. (Sherwood and Carter, 1970).

\section{Test programme}

A series of exprosure assessments had been made previously during which these specialist techniques were developed and tested. The present report describes the results of an intensive study of work on one summer day for which it was arranged that a maximum amount of petrol was loaded so that the highest likely exposure could be determined. The benzene content of normal petrol was about $2.7 \%$ by weight and of premium petrol about $4.5 \%$ by weight. The other products loaded did not contain significant amounts of benzene.

Unfortunately, the day started with thundery rain so that temperatures were not as high as those often encountered in summer and probably less of the product volatilized than is usual for the season. The exposure conditions are probably typical of general summer operations, which are worse than those in other seasons.

Personal air samples were taken over 15-minute periods on the two men handling the loading arms, and on the one man working in the weigh room. Breath samples were taken before work, at the mid-day break, at the end of work, and the following morning before work restarted. Urine samples were taken at the same time, and also before work began after the week-end break before the study.

\section{Results}

Air sampling results, which followed log-normal distributions, are shown in Fig. 3, and the essential information is summarized in the Table.

Breath sampling results (expressed in p.p.m.) are shown in Fig. 4; respirator results have been normalized to a standard moisture weight gain of $25 \mathrm{mg} / \mathrm{l}$ exhaled air.

The concentrations of phenol in urine $(\mathrm{mg} / \mathrm{l})$ are also shown in Fig. 4; normalized results are standardized to the mean specific gravity of all samples $(1.017)$ with a limiting factor of 2 .

In a control group of nine men not exposed to benzene at work, the mean value for total phenol (free plus conjugated) in urine was $1.8 \mathrm{mg} / \mathrm{l}$ with a maximum of $3.5 \mathrm{mg} / \mathrm{l}$. From these results it appears that the probability that $5 \mathrm{mg} / \mathrm{l}$ would be exceeded in the absence of benzene exposure is less than $1 \%$.

\section{Interpretation}

Neither loader was exposed to more than the 25 p.p.m. ceiling value (A.C.G.I.H., 1970), during any

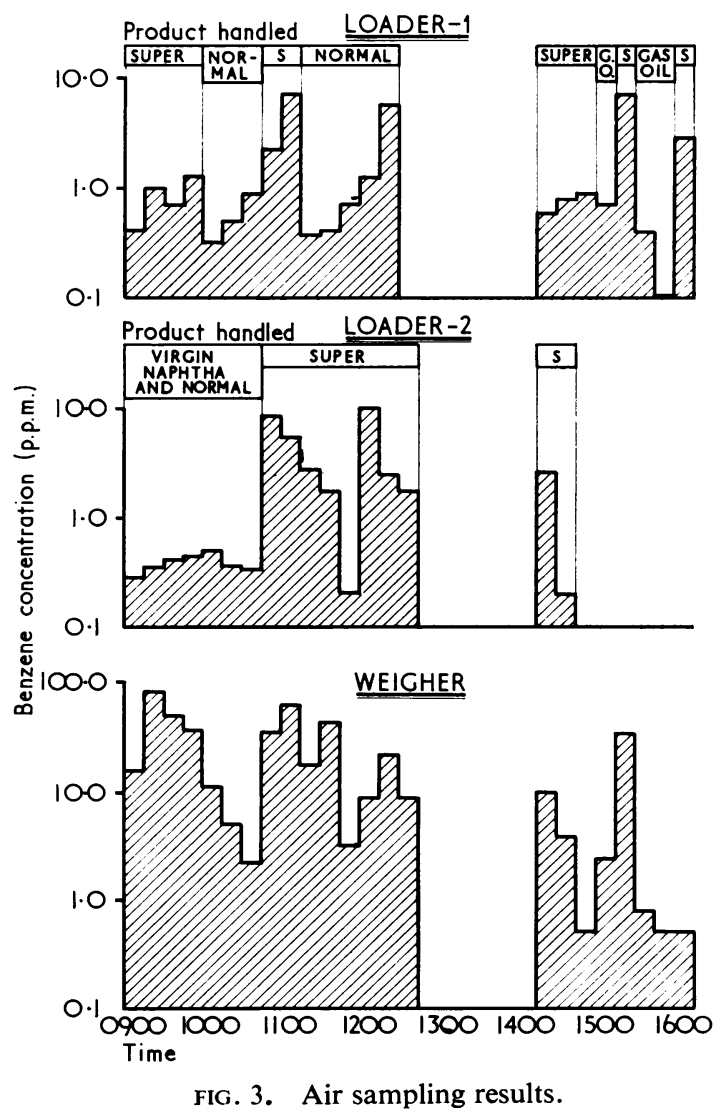


TABLE

Summary of AIR SAmpling Results

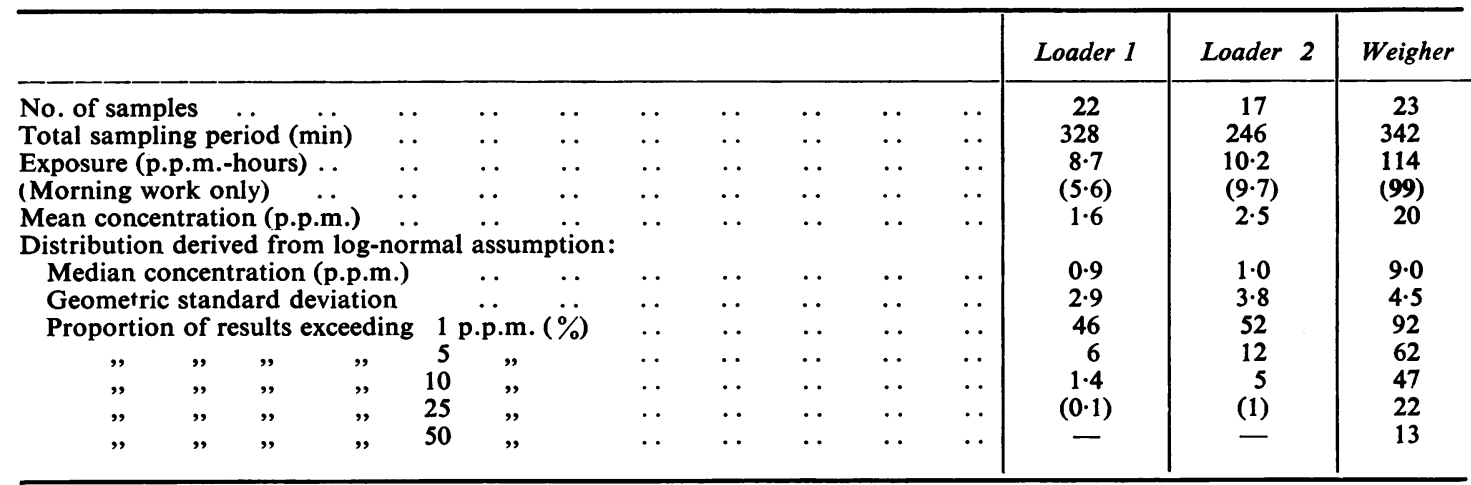

15-minute period and the mean exposure did not exceed the recently revised U.S. Standard of 10 p.p.m. as a time-weighted average (American National Standards Institute, 1969). Most of their exposure of about 10 p.p.m.-hours occurred during the morning, and the mean concentrations to which they were exposed during loading were 1.6 and 2.5 p.p.m., equivalent to $1 \cdot 1$ and 1.3 p.p.m. over an 8-hour day. In these particular conditions of work and climate it appears that the chance of their being exposed to concentrations greater than 25 p.p.m. in any 15 -minute period is 0.1 and $1 \%$.
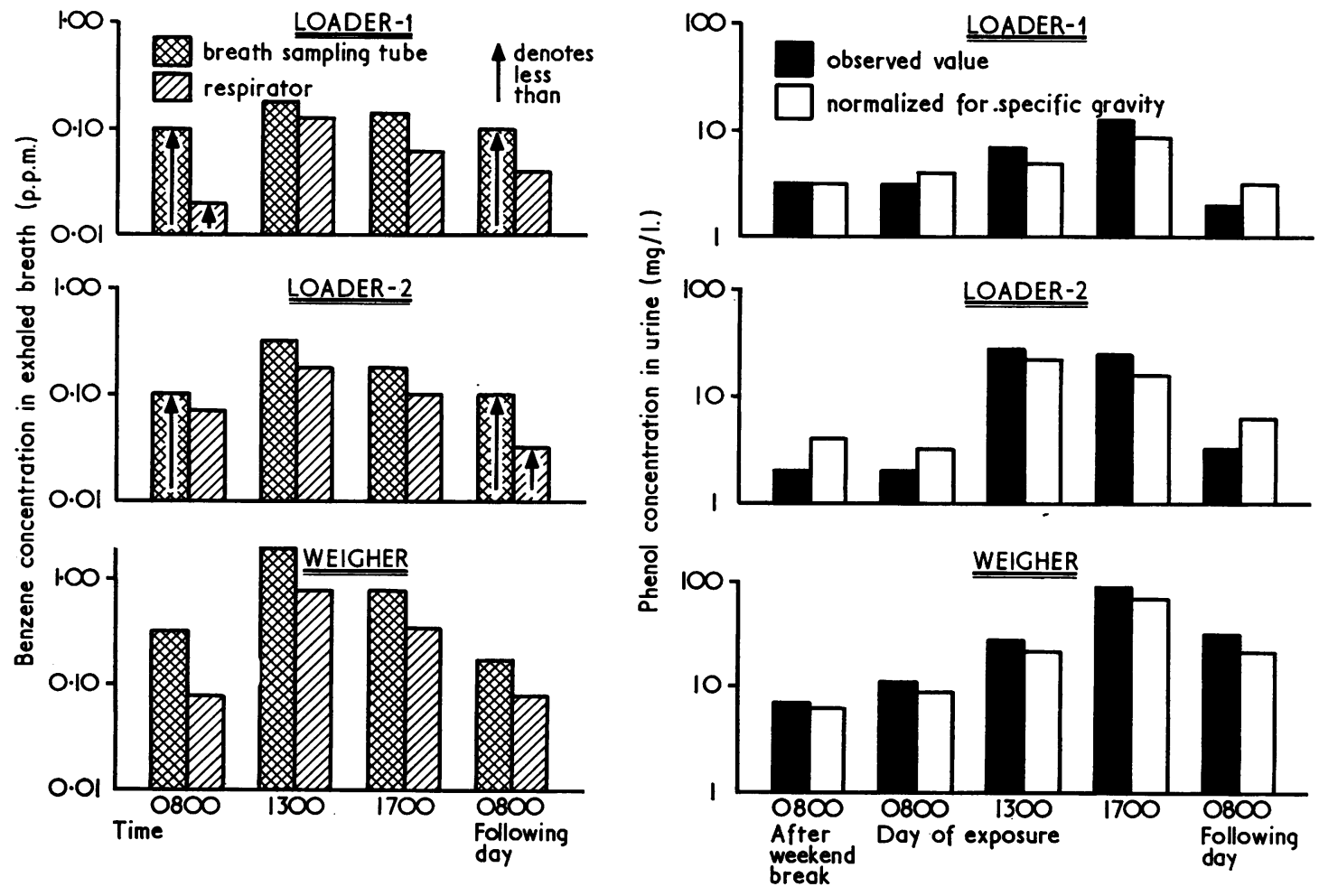

FIG. 4. Exhaled breath and urine excretion results. 
During 7 out of 2315 -minute periods the weigher was exposed to more than the 25 p.p.m. ceiling value. His total exposure of 114 p.p.m.-hours (of which 99 p.p.m.-hours were during the morning) corresponds to a mean concentration of 20 p.p.m. and was equivalent to 14 p.p.m. over an 8-hour day, which exceeds the A.N.S.I. Standard. In these conditions the probability of his being exposed to 15 minute average concentrations greater than 25 p.p.m. is $22 \%$.

No limits have been established for breath or urine sample results, though it has recently been proposed in this country that $100 \mathrm{mg} / \mathrm{l}$ should be taken as a biological threshold (Chief Inspector of Factories, 1970). This level was not exceeded in these operations.

In the experimental exposure made before this study 2 p.p.m. was measured in exhaled breath immediately after a few hours' exposure to 25 p.p.m., and 0.2 p.p.m. was observed the morning after a day's exposure to 115 p.p.m.-hours. By these criteria the loaders should have 0.13 and 0.2 p.p.m. in breath at the end of work, and less than 0.02 p.p.m. the following morning. The last value is below the sensitivity of the method, but the end-of-work values of 0.14 and 0.18 p.p.m. agree closely.

The exposure of the weigher would be expected to produce 1.6 p.p.m. in alveolar breath after work and 0.2 p.p.m. the following morning; in fact 0.84 and 0.19 p.p.m. were observed. Although the first is rather low, it should be noted that the operator's midday sample showed $2 \cdot 1$ p.p.m. and exposure after lunch was lower, though this was also true of the other men exposed.

From calculations based on the paper of Docter and Zielhuis (1967), urine samples taken after work would be expected to show 17 and $23 \mathrm{mg} / \mathrm{l}$ phenol for the loaders and $140 \mathrm{mg} / \mathrm{l}$ for the weigher. The actual values were 12,25 , and $83 \mathrm{mg} / \mathrm{l}$ or, normalized for specific gravity, 9,15 , and $71 \mathrm{mg} / \mathrm{l}$. These are lower than the expected values but rather higher than the 7,7 , and $60 \mathrm{mg} / \mathrm{l}$ that might be expected from linear extrapolation of the experimental results.

By the following morning the loaders showed natural background levels of phenol in urine and the weigher showed $38 \mathrm{mg} / \mathrm{l}$, or $25 \mathrm{mg} / \mathrm{l}$ when normalized. This is about one-half the end-of-shift value and less than the $55 \mathrm{mg} / \mathrm{l}$ predicted from his exposure. It will be noted that both breath and urine samples taken after a week-end show that some longer-term retention of benzene occurs in the weigher.

It is considered that the above results confirm the validity of all these methods for evaluation of exposure to benzene though further studies are needed before great dependence can be placed on breath and urine results. It appears most desirable that further studies should be made using these techniques wherever benzene is handled in industry so that, with appropriate clinical studies, a better assessment can be made of the hazard associated with any given level of exposure.

Although all the operators inhaled some benzene vapour, the only exposure that could be considered as significant on the basis of present knowledge is that of the weigher, though this is low when compared with the industrial exposures which were common in the past.

Based on previous measurements made at other times of the year, it is considered that these values probably represent the higher exposure of summer. A limited number of samples taken on earlier visits to the plant had shown mean values in summer of 5 p.p.m. for loaders and 14 p.p.m. for the weigher. In a previous one-day intensive study during the autumn season a loader had a mean exposure of 1.9 p.p.m. and the weigher 5.3 p.p.m. The probability of the 25 p.p.m. ceiling value being exceeded over any half-hour sampling period under conditions prevailing at that time was calculated to be $1 \%$ and $6 \%$ respectively.

Modifications are being made to the loading rack to reduce exposure of the weigher to levels below those of the loaders.

The author would like to acknowledge the kind permission of the management of the refinery and of Esso Standard Italiana to publish this article. He thanks members of the medical departments for support and encouragement, and the plant supervisor and the operators for their complete co-operation throughout the study.

\section{References}

American Conference of Governmental Industrial Hygienists (1970). Threshold Limit Values, Cincinnati.

American National Standards Institute (1969). Acceptable Concentrations of Benzene, Z 37.4.

Chief Inspector of Factories (1970). Annual Report, 1969. Cmnd. 4461, p. 61. H.M.S.O. London.

Docter, H. J., and Zielhuis, R. L. (1967). Phenol excretion as a measure of benzene exposure. Ann. occup. Hyg., 10, 317-326.

Hunter, C. G. (1968). Solvents with reference to studies on the pharmacodynamics of benzene. Proc. roy. Soc. Med., 61, 913-915.

Joint ILO/WHO Committee on Occupational Health (1969). Permissible Levels of Occupational Exposure to Airborne Toxic Substances. Wld Hlth Org. techn. Rep. Ser., No. 415. WHO, Geneva.

Levine, L., and Fahy, J. P. (1945). Evaluation of urinary lead determinations. J. industr. Hyg., 27, 217-223.

Sherwood, R. J., and Carter, F. W. G. (1970). The measurement of occupational exposure to benzene vapour. Ann. occup. Hyg., 13, 125-146.

Stewart, R. D., and Dodd, H. C. (1964). Absorption of carbon tetrachloride, trichloroethylene, tetrachloroethylene, methylene chloride, and 1,1,1,trichloroethane through the human skin. Amer. industr. Hyg. Ass. J., 25, 439-446.

Received for publication March 12, 1971 